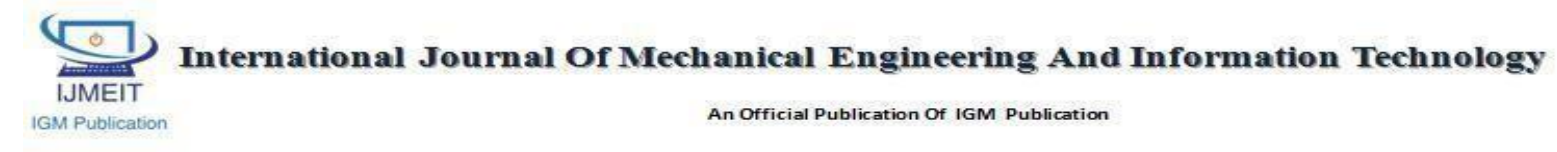

Index Copernicus Value-63.45

\title{
Design and Development of Man Driven Pesticides Spraying Machine
}

\author{
Authors \\ Suraj Thombare', Sumit Kale², Shailesh Yadav', Shailesh Patil ${ }^{4}$, Shubham Mahajan ${ }^{5}$, \\ Shubham Gedam ${ }^{6}$, Prof.Ashish Taywade ${ }^{7}$ \\ 1,2,3,4,5,6 Department of Mechanical Engineering R.T.M.N.U, Nagpur \\ ${ }^{7}$ Assistant Professor of Mechanical Engineering R.T.M.N.U, Nagpur
}

surajthombare08@gmail.com,svkale12.12@gmail.com,yshailesh786@gmail.com,Shaileshpatil916@gmail.c

om,shubhammahajan132@gmail.com,Shubhamgedam150@gmail.com,antaywade@gmail.com

\begin{abstract}
India is an agricultural based country, maximum population of India depends upon farming. Our farmer used traditional methods and equipment's for farming purpose such as spraying, weeding, seed sowing. Due to this reasons they are lacking in quality and productivity. Modernization of agricultural sectors is a need of time. The traditional spraying is laborious, requires more human effort. We proposed a new mechanism which provides the solution to improve productivity by overcoming the drawbacks of traditional equipment. It is portable, operate without fuel and convenient to operate.

Keywords: Agricultural Sector, Pesticide Spraying Machine, Mechanization, Productivity, Human fatigues.
\end{abstract}

\section{INTRODUCTION}

India is a land of agriculture; most of the population in India is dependent on farming for its livelihood. The economic conditions of average Indian farmers are poor and hence they cannot afford large automatic effortless mechanization for their farms. Spraying is an essential component of farming as it is important to spray the pesticides to improve the efficiency of yields and meet the growing food requirements of India. The average Indian farmer is using conventional methods for spraying of crops, these methods includes the knapsack sprayer which has to be mounted on back and requires the lever to be operated manually in order to spray. Continuous weight on back of farmer leads to back pain and manual pumping leads to wastage of efforts of the farmers. There is need to reduce this efforts, and speed up the spraying application in the field. The study of practices of farming in India is important for the effective design of a new kind of sprayer. Thus, a significant opportunity rests with understanding the impact of a pesticide sprayer in an agriculture field. A pesticide sprayer is a portable and with an increased tank capacity as well as should result in reduction of cost, labour and spraying time. The conventional sprayer having the difficulties such as it needs lot of effort to pushing the liver up and down for creating the pressure to spray. Another difficulty of fuel operated sprayer is to need to purchase the fuel which increases the working cost of the sprayer. In order to overcome these difficulties, I have proposed a wheel driven sprayer, it is a movable device and no need of any fuel to operate, which is easy to move and sprays the pesticide by moving the wheel. The mechanism used in this sprayer is reciprocating pump, and nozzles which were connected at the front end of the spraying equipment.

\section{PROBLEM IN EXISTING SPREYER}

The Indian farmers are presently using lever operated backpack sprayer. A backpack sprayer consists of tank 18-25 liter capacity carried by two adjustable straps. Constant pumping is required to operate continuously this which result is to create back pain of operator; also the backpack sprayer 
cannot maintain constant pressure, result spindrifts or dribbling. Developing adequate pressure is laborious and time consuming. Pumping to operating pressure is more time consuming. It also results very small area is covered while spraying. So, more time are required to spray the complete land. Back pain problems may come during middle age operator due to carrying of 18-25 liter tank on back.

\section{NEED OF WORK}

For observing the many problems of farmer for fertilization in agriculture sector the need of modernization is important, So in order to have solution to it, it was proposed to manufacture a pesticides / Fertilizer Spreader machine. Hence, the farmers can work easily and very fast.

The following objectives are satisfied for this sprayer.

Fertilization process consume less time.

Portable to handle

Driven by manually

Light in weight

Less operating cost by using new mechanism.

Comparative less operating efforts required.

\section{DEVELOPMENT OF MACHINE}

The following parts used in the Machine:

Shaft

Wheel

Chain and Sprockets

Crank Mechanism

Sprayer tank

Nozzle

Shaft: A drive shaft is a component for transmitting torque and rotation, usually used to connect other components of a drive mechanism that cannot be connected directly because of distance or the need to allow for relative movement between them. The torque carriers, drive shafts are subject to torsional and shear stress, similar to the difference between the input torque and the load. They must be strong enough to bear the stress, whilst avoiding large additional weight as that would in turn increase their inertia.

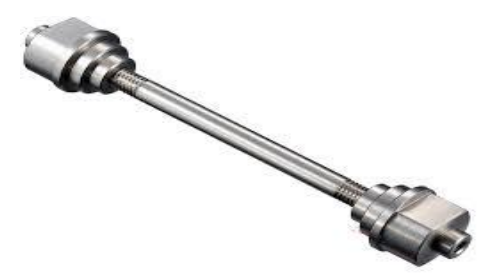

Figure:Shaft (axel)

Wheel: A wheel is a circular component that can be rotate on an axial bearing. The wheel is one of the main components of the wheel and axle which is easy to rotate. Wheels, in conjunction with axles, allow heavy load to be moved easily facilitating movement or transportation while supporting a load, or performing labour in machines. A wheel also reduces the friction by facilitating motion to rolling together with the use of wheel axles.

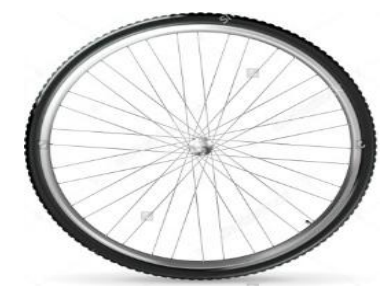

Figure: Wheel

\section{Chain and sprocket:}

Chain drive is a way of transmitting mechanical power from one place to another place. It is often used to bring power to the wheels of a vehicle. Most often, the power is dispatched by a roller chain, known as the drive chain or transmission chain passing over a sprocket gear, with the teeth of the gear meshing with the holes in the links of the chain. The gear is turned, and this forces the chain putting mechanical force into the system.

A sprocket or sprocket-wheel is

a generalized wheel with teeth, cogs or even sprockets that mesh with a chain, track or indented material. The sprocket applies generally to any wheel upon which radial projections engage a chain passing over it.

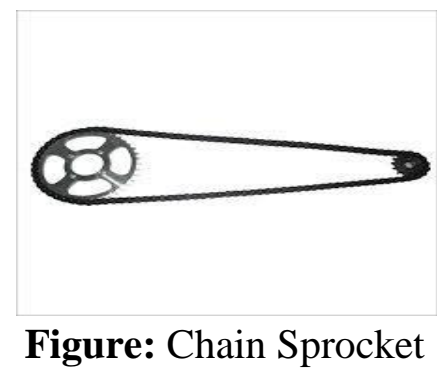

Crank: A crank is an arm attached at to a rotating shaft by which reciprocating motion is admitted to 
or received from the shaft. This mechanism is used to convert circular motion into reciprocating motion. The one end of the connecting rod attached to the crank moves in a circular motion, while the other end is move to linear sliding motion.

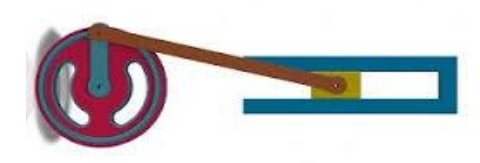

\section{Figure: Crank (mechanism)}

Sprayer tank: The tank should be made of a corrosion-resistant material. Materials used in sprayer tanks include stainless steel, polyethylene plastic and fibres. Pesticides may be corrosive to certain materials. Aluminium, galvanized and steel tanks should not be used. Some chemicals react with these materials, which may result in reduced effectiveness of the pesticide, or rust or corrosion inside the tank. Keep tanks clean and free of rust, moisture and other contaminants which can damage the pump and nozzles. Also, contamination may collect in the nozzle and restrict the flow of Chemical, resulting in improper spray patterns and rates of application. The tank should be clean after spraying is completed. A tank should provide a drain hole at the bottom near one end helps allow complete drainage.

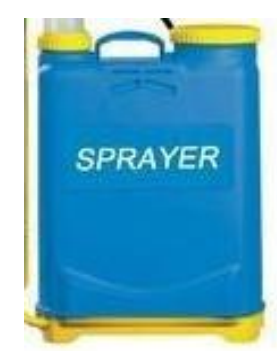

Figure: Sprayer tank

Nozzle: The nozzle is an important part of any sprayer.it performs three functions:

1. Regulate flow

2. Atomize the mixture into droplets

3. Disperse the spray in a desirable pattern.

Nozzles are made from several types of material such as brass, plastic, nylon, stainless steel, hardened stainless steel, and ceramic. Nozzles made from harder metals usually cost more but will usually wear longer. Each nozzle on a sprayer should apply the same amount of pesticide. If one nozzle applies more or less than adjoining nozzles, streaking may occur. Nozzle flow rates need to be monitored by regularly collect to the flow from each nozzle under operating conditions and compare the output. The nozzle should be removed from the nozzle body and cleaned it with a soft bristled nozzle cleaning brush. Blowing the dirt out with compressed air is also a good method.

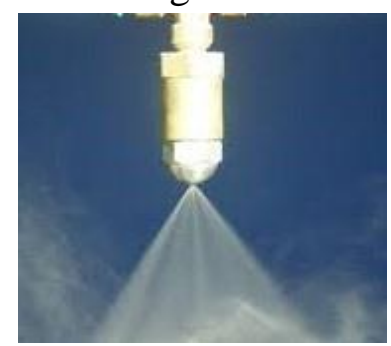

Figure : Nozzle

\section{WORKING DIAGRAM}

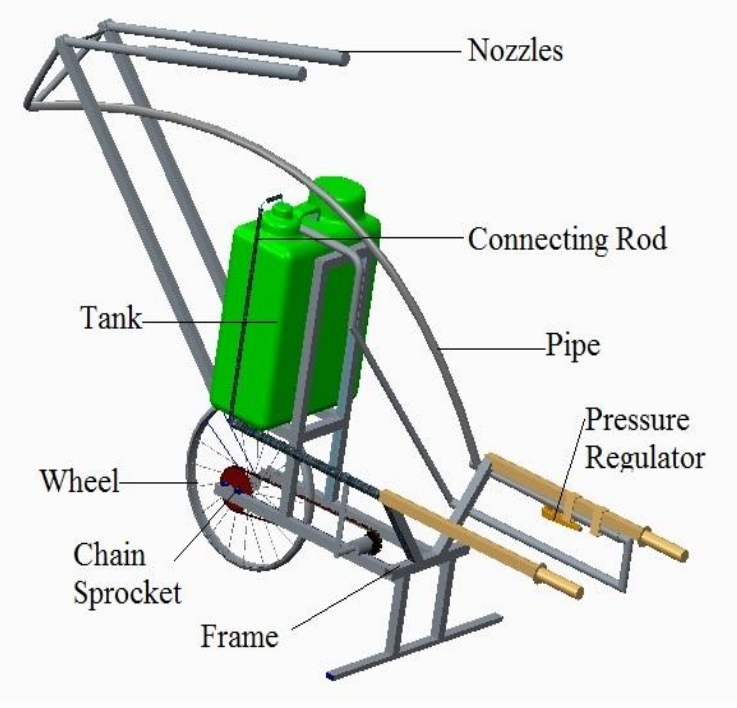

Fig:CAD Model of sprayer

When the machine is push forward by using handles, the wheel rotates and the bigger gear is mounted at the axle of wheel is start to rotate and its rotation is then transferred to the smaller gear through the chain drive. The ratio between the two gears is $1: 2$. This rotary motion of the smaller gear is converted into the reciprocating motion by the slider crank mechanism, due to this arrangement the connecting rod moves up and down motion which then reciprocate the piston of single acting reciprocating pump mounted in the storage tank. During the upward and downward motion of 
connecting rod the reciprocating pump creates suction and compression in the cylinder, the pressure generated in the cylinder is passed through the delivery pipe and pesticide is forced to the delivery valve, this delivery valve is connected to the pipe carrying the number of nozzles. When the delivery valve is open the pressurize pesticides is spread on the craft.

\section{CONCLUSION}

The objective of our project was to fulfil the need of farmer's difficulty from the problems of increasing cost of Fertilization, labour cost and availability as it is operated by single person. This project is an effort to fulfil the entire requirement discussed earlier. The wheel operated reciprocating pump is strictly designed taking into consideration all the mechanical term that are related to design of pump. The reciprocating pump is mounted on tank and that's why they can be transported easily. All the thing are aimed towards the less effort required to operate the pump. The pump is a light duty component capable of sprayed high pressure liquid through nozzle. It reduces man power for operation. Maximum quantity of liquid can be carried (up to 25 lit. depending on tank size) and also can be utilized It can spray on tall trees with adjustable nozzle.

To produce more output from the farm and also it gives more productivity in less input. By using this mechanism we can reduces the efforts of labours and constantly spray the fertilizers and pesticides all over the farm.

\section{ACKNOWLEDGMENT}

The authors are thankful to Prof. A.N. Taywade, Assistant Professor, and also the Faculty of Mechanical Engineering Department, N.I.T. College of Engineering Nagpur, for providing the necessary facilities for the preparation of the paper.

\section{REFERENCES}

1. Dr.R.N. Panchal Sir and Mr. Nikhil Deshmukh "Monowheel Operated Pesticide
Spraying,Machine",volume:2,Issue:,IERJ,20 15,pp.1-4,

2. Shivarajakumar, Parameswaramurthy "DESIGN AND DEVELOPMENT OF WHEEL AND PEDAL OPERATED SPRAYER" volume 2 Issue 6, IIJME ,July 2014, ,PP 22-25

3. Narode R. R., Sonawane A. B., Mahale R. R., Nisal S. S. , “ Manually Operated Fertilizer Spreader” volume 2, Issue 5, IJETAE, February 2015, PP 369-373.

4. Ntish Das, NamtMaske and S.K. Chaudhary," Agricultural Fertilizer and Pesticides Sprayers -A Review", volume 1, Issue 11,April 2015, PP 44-47.

5. Prof. Sumit Raut ,prof. Kamlesh r. Banarse, prof. Roshan r. More, "fabrication of pedal operated reciprocating pesticide sprayer for agricultural and drainage line use" ,Volume 9 Issue 9, IJPRET, may 2014,PP 67-74.

6. Sandeep H. Poratkar, Dhanraj R. Raut, “ Development of Multinozzle Pesticides SprayerPump", ISSN: 2249-6645, Vol.3, Issue.2, March-April. 2013 pp-864-868. 